\title{
Strategic Financial Management Review on the Financial Success of an Organization
}

\section{Mohammad Delkhosh}

\author{
Islamic Azad University, Bardaskan Branch, Department of Accounting, Bardaskan, Iran \\ Email: mdelkhosh54@iaubc.ac.ir
}

\section{Hamideh Mousavi}

Executive Management Degree in M.A-Islamic Azad University,Neishabour Branch Email: Parseh.mousavi@gmail.com

\section{Doi:10.5901/mjss.2016.v7n2s2p30}

\begin{abstract}
The management capabilities as one of the powerful and main stimulating items of development are a subject that has always been validated by the experts and executives. The strengthening of the financial management as one of the most important abilities of the managers of the enterprises is accounted as the effective practical tools in the guideline route and management of companies and enterprises and execution of the growth and development strategies. The focus of strategic financial management is on the state of the management of a company and the adoption of the suitable strategies during the economical downturn and entry of the companies to the emergency financial stage and increase of the whole risk. The strategic financial management also conducts the study of resources and consumptions of each organization besides defining the degree and extent of the presence of the managers in an organization for realization of the related targeted activities on the state of the conduction of the expenses of an organization, the methods for the collection of incomes and the manner of the aspects management and financial resources is its responsibilities. The vision of financial strategic in the form of strategic action means an imaginary understanding of the optimal position of an organization and having a picture of a clear and desirable tomorrow. This thinking guides executives to moving the strategy of an organization towards the success and better financial policies. The realization of stability and long-term purposes of an organization, is more balanced than the payments and assessment of capital and explanation of the methods and strategies to collect wealth for the shareholders is one of the targets of the strategic financial management that the realization of these goals propels an organization towards the everincreasing financial success.
\end{abstract}

\section{Introduction}

It is obvious that in today's world the success of organizations is achieved via simultaneous activities. Most of the execution managers have a viewpoint on an issue that the best route in front of the superior financial executives for the acquisition of assurance from the success of their company, is allotment of more time on the strategy; the timely control of the warehouse inventory, the production and after sale services, innovative products and finances and control of the commercial risks and others are advancing towards standardization, with the existence of simultaneous activities of different organization sections, in the strategic financial management module, the integration of strategies and financial issues adds to the success of an organization. In this regard, the financial strategies in order to access a clear strategy to guide the future production, avails a suitable criteria for the evaluation of the performance of an organization. The financial management handles the allocation of scarce resources in an organization and targets its strategies for distinguishing itself from its competitors.

The planning of important financial management strategic relates to this concept that financial aspects for the strategic management of its related cases will be considered as a different case. The financial management for the consolidation of its activities role in the strategy of an organization should assist in the gathering of the information related to the three principles of strategic viz. quality, cost and time and establishment of the relationship between the daily activities of an individual in an organization with the codified strategy subjects encounters a special importance. The financial management information assists an executive to determine the qualitative targets via measurement of the consumed resources for the prevention of the possible production defects, the cost of reconstruction of the defective productions, the cost of performing the repairs and the maintenance of the equipments, the lost sale opportunities due to lack of the products quality and new investment for increasing the product quality and to analyze the effects of quality costs to reach the profit and eventually the financial success of an organization is gained. 


\section{The Strategic Financial Management Role in the Financial Success of an Organization}

The several alterations that have been created in the recent years in the commercial environment have compelled the economic units to face expansive challenges. One of these challenges is the intensification of global competition, and the increase in the number of companies has manifested this fact that the managers for the increasing profitability should make use of the existing opportunities in the international markets. Likewise, the technology development, has forced many institutions to use the new technology that has made the possibility of mass production possible in a short span of time. With the use of the strategic financial management the progress of an organization from the viewpoint of managers' performance and financial growth of an organization will be possible. An emphasis on the customer orientation, the evolution in the management of the organizations, the timely delivery of products and services and innovation in the production, are the other important cases that the managers should pay attention to them. On the other hand, the social, political and cultural changes has increased the flexibility and adaptation abilities of the institutions, and consideration of the organizational external factors and production of goods or conduction of the services in accordance with the needs of the customers in the global scale, has achieved much importance. The execution of strategies necessitates that an organization considers its annual goals, determine the policies, creates a motivation in the staffs and assign the resources in a manner that the formulated strategies are implemented.

The assessment of strategies - the strategies should be assessed since the success of today cannot guarantee tomorrow's success. Prior to anything else, the strategic management is an excellent task management, because the success if fully related to the future of an organization and the effort in specification of the context has an aim to the orientation of the main tasks of the managers. He thinks that in the specified periodic horizon, what will be the organization and for acquisition of these results which tasks should be carried out. The financial strategies of an organization are in association with the other strategies and the success of an organization is in the shadow of the favorability of these strategies. In the following diagram, the relationship between these strategies has been depicted.

The organizations in the environment that they are nestled have a correlation and interaction within one another. Whatever changes takes place in an environment the organization also accepts an effect from it. For this reason the strategic management will chase the environment from proximity. The financial management as well as the strategic management is both the complete interdisciplinary methods that integrates into a very useful method and leads to strategic financial management. The strategic financial management has not been accepted in an expansive manner since it is specified with a wide range of methods or has been limited to the special methods. The strategic financial management specifies the goals, decisions and the activities in an organization and up to the lowest levels determine the initiation movement point for each person.

Overall the financial strategic of an organization is codified through the stages that includes the state of how to meet the customers' preferences, the allocation of resources and the execution of new strategies for the customer satisfaction, the evaluation of performance and the assessment of successes and failures due to the business. So, it seems that the financial strategy is the most oriented strategy of an organization therefore the interaction of it with other organizational strategies are encountered with high importance.

In the strategic financial management three types of management are considered: investment strategy management, the financial provision and ultimately the profitability and the optimal combination of these three strategy kinds and its optimum management, will encompass the financial success of an organization. The financial executive of the company is continuously encountered with decision in these three modules and seeks an access to the combination of the policies and decision in order to correctly guide the institution in these three modules that finally fulfills the aim of value creation and maximization of the wealth. The basis of value creation that is the final aim of the activity of an economical organization and is the financial management knowledge is situated on these three simple principles: the hope that the monetary that is availed via the company or the economical organization is more than the money that you enter it. On this basis the financial management looks forward that with an efficient management create the short term and long term cash flows and an increased cash phases. Among the most basic decisions of financial managers of an organization is the knowhow of financial provision of a company with the lowest possible cost and the financial leverage has a significant role in the structure of the capital of a company. After the creation of the capital for an organization that is with an aim of cutting down the capital cost, the capital structure is followed, the state of the optimal investment is one of the tasks of the strategist financial managers of an organization that the financial strategy with determination and completion of the financial policy govern it on an organization. Eventually, the interest division section is under consideration that the accumulated profit as a financial provisional source can be divided as a share or in the form of a cash.

The strategic financial management is the collection of management decisions and actions that determines the 
long-term performance of a company. The strategic financial management includes the environmental assessment, strategy formulation, strategy implementation, evaluation and control. Therefore, the strategic management focuses and assesses the opportunities and foreign threats and emphasizes in the shadow of considering the strength and weakness points of a company. The objective of strategy compilation is that the company's mission is determined. In fine, it is identification of the factors that in an external environment either threaten an organization or create the opportunities. It relates to identification of the internal weak and strong points of an organization, setting the long-term objectives, considering the various strategies and selecting the specific strategies in order to continue the activity.

The source should create a value, or in other words, either reduces the costs or increases the price of the commodity. The rare and invaluable resource should also be difficult to be imitated. In order to avoid the duplication of competitors and maintain the resource competitive advantage, some obstacles should exist. A source and its output and exit are only imitable when the competitors could create or obtain the same resource. An emphasis on the strategy components and contents such as the competitive position and its relation with the performance of a company is out of the center of attention and the researchers should focus on the state that how a company makes a suitable competitive position and which factors cause that a specific performance is obtained. The strategy process of researchers has a focus on the state of a manager that how he could continually have an impact on the strategic position of a company via suitable decisions and utilization of administrative systems. The purpose of administrative systems is organizational structure, planning, control, motivation, human resources management and the value system of a company. The strategy process approach considers that how an efficacious strategy is formed in an organization besides giving an importance to it and its effective execution.

\section{The Perspectives of an Organization's Financial Success in the Ray of Strategic Financial Management}

The concept of strategic financial management is planning and control which define the rules of management accountants with the management control and functional control of the activities. The strategic financial management conducts the needed predictions and the financial information analysis in the markets of products, companies and the competitors' costs and cost structures and maintenance of the strategy of the companies and the items related to the competitors in these markets in a number of the courses. The term strategic financial management refers to the internal finance or management that with appropriate and needed measures for the monetary information in the management is investigated for a range of the targets. The cost acquisition of cost, the financial management performance has been provided with the information necessity for the assessment of stocks and the similar objectives.

The financial management is a strategic factor that causes the multifunctional method for the efficient management challenges. The role of financial management is for the provision of information that is related to the strategic management task, because in the practice it could considers the very different formations depending on the state of unique management decisions to follow their common goals, and these cases have a significant role in the financial success of an organization. The decisions that are taken for the acquisition of assurance from the effective allocation of resources, requires a variety of accounting information that accounting management alone could provide it for the managers.

The strategic financial management can be defined as a process for identification, collection, selection and analysis of the financial data for the assistance to the team of management for the strategic decisions and effectiveness organizational assessment. Establishment of a relationship between the provided information via the accounting management with the company aims is the only method to change the accounting management to a useful tool for the decision making. In this term, it is needed that the financial management and the company management have the complete participation. The strategic financial management is remembered as a response to the criticisms and it is an attempt that is conducted via the management accountants so that are surmountable on the introvert nature of the financial management.

The organization planning and the mode of minutes planning, the successful methods in the employment, the practical principles of increasing the efficiency of personalized sale and marketing, the procurement and operations, the principles of internal controls in the financial section and other cases with a correct strategic management is efficiently covered by the organization. The information in the strategic financial management includes all the financial and nonfinancial information needed by the managers and the information relevant to revenues and costs, is limited only to the short-term courses. While the economical units for success should consider the non-financial information even in their planning. Some believe that the financial management is an evolutionary of the financial management and some know it as a more ambitious stage of financial management, but in any case the strategic thinking has caused that the management accountants have expanded the sphere of the information to the level of the Managing Director and achieve 
a more important role in the assessment of critical success factors and the acquisition of these vital factors will open a window to the financial success of an organization.

In the administration of organization in accordance with the strategic financial management, the internal factors, including the financial ability, intellectual capital, organizational structure, the employee morale, the profitability and the external factors such as political, legal, economical, social and cultural, technological factors and competition are being assessed. In this route the value chain analysis, the life cycle analysis of the products and the matrix adjustment of the products have been exploited and even the weak and strong points, opportunities and threats are identified and with the comprehensive performance management and patterning, the financial success factors are identified.

The strategy besides the enforcement of the principles and management catechism in the organizations and communities determine the destination or the outlook and the route to reach that destination and specifies to the organizations that always observes itself in a competition field and are compared with the similar competitors or organizations and this does not create any limitations due to the nature of the organizations. In the process of compilation of the destination and route strategy with an authenticity on the internal abilities and capabilities of an organization and even is designed on the environment conditions. Therefore, according to the strategic financial management principles a professional accountant involved with an organization is a team of the senior management and carries out his duties for the strategy development and the implementation with an aim to create the customers and the share value and a powerful competition position for an organization in order to access the strategic target of an organization i.e. financial success.

In the financial management an effective strategic is considered, in general the organizational effectiveness is an access to the priorities and the multiple targets in the framework of common value system with the organizational culture. In a manner that the acquisition of the targets from the cost and time viewpoint is optimal and provides the satisfaction for the benefactors that are striving towards the acquisition of their goals and definitely this satisfaction is the same financial satisfaction of an organization.

\section{Results}

The experimental studies have shown that most of the competitors have faced failure when encountering with the strategies of the big companies during an execution. For determination of the access limit to the goals, the executed strategy should be controlled as well as monitored. The financial criterion in the implementation and monitoring of the companies' strategies, with specific financial objectives related to the industry assist in the measurable and increases the capabilities of an organization. They create the stable competitive advantage that increases the corporate value and reaches the main aim of the entire benefactors. Besides, the development of service provision for the customers as one of the most important internal strategic factors has a direct influence on the financial success of an organization. Undoubtedly, this work should be carried out via the section of an organization that has a comprehensive outlook and could form a balance and equilibrium between the objectives and needs of today and the requirements of tomorrow and also could assign the human and financial resources in a manner that terminates to the main and the desired results. For the codification of the strategies, in an effective manner, the weak and strong points of an organization should be determined from the financial viewpoint. An epilogue is that every organization under the strategy management turns more profitable, thus the financial success of an organization under the execution of a strategic financial management is a clear imperative.

\section{References}

Ali Rezaeiyan. Organizational behavior management (concepts, theories and applications). Tehran, Management Faculty Publications, Tehran University, 1993, pp. 266-267.

Ali Delavar. The statistical methods in psychology and educational sciences. Tehran: Payam-e-Noor University Publications, 1994, pp. $246-247$.

Kourosh Fathi Vajargah. An acquaintance with the in-service training of staffs (education management and planning and staffs). Tehran: Total Administration of In-service Training Publications, 1994, pp. 34-35.

Mohammad Farahmandiyan. The importance of training for teachers. Teacher Development Journal. Nineteenth Year, December, 2000, Issue No. 153.

Reza, Zarinfard. A glimpse into the performance of the department of teacher education, and .... The Journal of Management in the Education and Training, Vol. VI, No. 23-34, Autumn and Winter 1994, pp. 97.

Richard, M; S. and Lyman W., Porter.Motivations and behavior in the work. Translator: Sayyid Aminullah Alavi. Vol. I. Tehran. State Management Training Center Publications, 1993.pp. 49. 
Ruth Bender and Kit Ward: Strategic planning, corporate, financial affairs. Translators: Seyed Mohammad Arabi and Muharram Razmjooeii. Tehran, Mahkame Publications, 2012.

Stephen P. Robbins. The Organizational behavior (Concepts, theories, applications). Vol. I. Translators: Ali Parsaiyan and Seyed Mohammad Arabi. Tehran: The Cultural Researches Office Publications, 1998. 